\title{
DIFFUSION MECHANISM OF WATER VAPOUR IN A ZEOLITIC TUFF RICH IN CLINOPTILOLITE
}

\author{
F. Çakıcıoğlu-Ozkan ${ }^{*}$ and S. Ülkü \\ Chemical Engineering Department, Izmir Institute of Technology, Gülbahçe Köyü, 35430 Urla, Izmir, Turkey
}

\begin{abstract}
The adsorption kinetics of $\mathrm{H}_{2} \mathrm{O}$ in a clinoptilolite rich zeolitic tuff was experimentally investigated at $18^{\circ} \mathrm{C}$. In the identification of the diffusion mechanism the isothermal adsorption model equation was used. It was found out that the intraparticle mass transfer becomes more dominant over the heat transfer with increase in particle size and the adsorptive dose pressure. Although initially intraparticle mass transfer was the controlling resistance later external heat transfer also contributes to the transfer mechanism.
\end{abstract}

Keywords: adsorption, clinoptilolite, diffusion, gravimetric system, water vapor

\section{Introduction}

Zeolites are crystalline, hydrated alumina silicates of group 1 and 2 elements, consisting of $\mathrm{SiO}_{4}$ and $\mathrm{AlO}_{4}$ tetrahedra linked by oxygen atoms to compose the framework. In the zeolite framework, each aluminum atom introduces one negative charge on the framework which must be balanced by an exchangeable cation $\left(\mathrm{Ca}^{2+}, \mathrm{Mg}^{2+}, \mathrm{Na}^{+}, \mathrm{K}^{+}\right.$, etc.). The exchangeable cations located within the framework play a crucial role in adsorption and thermal properties of the zeolites. Clinoptilolite, one of the most common natural zeolite mineral, is a member of the heulandite group [1]. Its framework structure consists of three channels. The channel $\mathrm{A}$ and B, 12-membered $(0.75 \times 0.31 \mathrm{~nm})$ and 8 -membered $(0.46 \times 0.361 \mathrm{~nm})$ tedrahedral rings respectively, are parallel to each other while the channel C, 8-membered $(0.47 \times 0.28 \mathrm{~nm})$ tedrahedral ring, intersects the channel A and B. Since water is selectively adsorbed by natural zeolite it hinders the adsorption of the other molecules. Although the kinetic data related to wateradsorbent system is quite important both in gas separation and purification, desiccant cooling, drying [2-6], energy storage system [7, 8], swelling properties of the wool [9], organic and inorganic polymers [10], water-zeolite system was studied seldom $[11,12]$.

In this study the diffusion mechanisms of water vapour in a natural zeolitic tuff were compared theoretically and experimentally at $18^{\circ} \mathrm{C}$. The apparent diffusivity was obtained from the experimental uptake curve by the isothermal adsorption rate models. By comparison of the apparent diffusivities obtained from two different particle sizes, the controlling step of the diffusion rate could be determined to be either macropore or micropore diffusion.

\section{Experimental}

The zeolitic tuff from Bigadiç, Türkey having the chemical composition (mass\%): $\mathrm{SiO}_{2}: 71.75$, $\mathrm{Al}_{2} \mathrm{O}_{3}: 10.91, \mathrm{Fe}_{2} \mathrm{O}_{3}: 0.54, \mathrm{MgO}: 1.08, \mathrm{CaO}: 2.30$, $\mathrm{Na}_{2} \mathrm{O}: 1.19, \mathrm{~K}_{2} \mathrm{O}: 4.3, \mathrm{TiO}_{2}: 0.17, \mathrm{MnO}: 0.0008$, $\mathrm{H}_{2} \mathrm{O}: 7.77$ was used. It is identified as clinoptilolite rich mineral with high $\mathrm{Si} / \mathrm{Al}(>4)$ and having $(\mathrm{Mg}+\mathrm{Ca}) /(\mathrm{Na}+\mathrm{K})$ ratio of $0.52[12,13]$. The clinoptilolite rich tuff was crushed and spherical particles with approximately 0.26 and $0.32 \mathrm{~cm}$ diameter were obtained by trimming. The kinetics of water vapor adsorption on the 0.26 and $0.32 \mathrm{~cm}$ diameter clinoptilolite particles was measured by using the gravimetric microbalance (Cahn 2000) system (Fig. 1). The sample was hanged by a nichrome wire for weighing. For approaching isothermal condition the bottom of the hang down tube is made out of covar metal so the generated heat during adsorption can be easily conducted by contacting the sample to covar metal between measurements. The clinoptilolite rich mineral was regenerated for $17 \mathrm{~h}$ at $400^{\circ} \mathrm{C}$ under a vacuum $\left(10^{-3} \mathrm{~Pa}\right)$ and cooled to $18^{\circ} \mathrm{C}$ before each adsorption experiment. Water vapor was allowed to flow into the system for a short period of time by using a fine needle valve up to desired dose pressure $\left(P_{\text {dose }}\right)$ and the mass change $v s$. time was recorded till equilibrium pressure $\left(P_{\mathrm{e}}\right)$ was attained. The pressure of the water vapor in the system was measured by

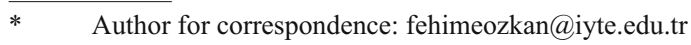




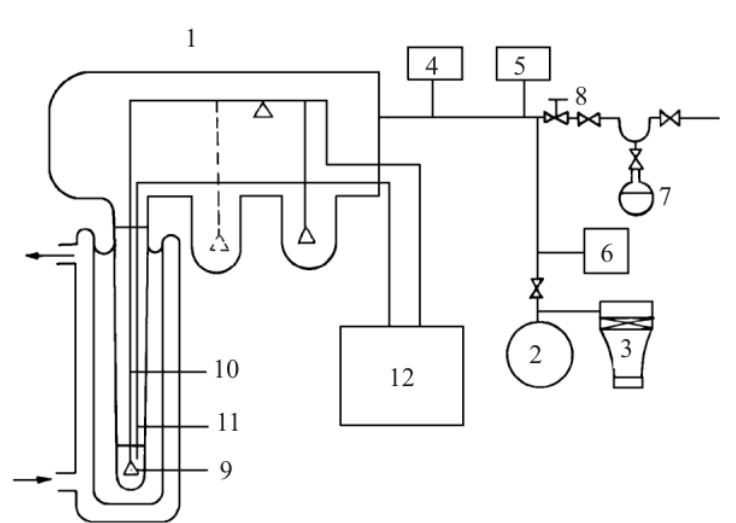

Fig. 1 Chan gravimetric adsorption system; 1 - microbalance, 2 - vacuum pump (Edwards E2M2), 3 - diffusion pump (Edwards Diffstak 250), 4 - pressure transducer (0-200 Pa), 5 - Penning gauge, 6 - EMV 251: 0-10 5 Pa pressure gauge, 7 - water reservoir, 8 - BRY needle valve, 9 - zeolite sample, 10 - nichrome wire, 11 - thermocouple, 12 - recorder

using two different pressure transducers with $0-200 \mathrm{~Pa}$ and $0-10^{5} \mathrm{~Pa}$ ranges.

\section{Results and discussion}

The rate limiting steps in water vapor adsorption may be the external mass transfer, intraparticle mass transfer (micropore and macropore) and external heat transfer. For the clinoptilolite-water vapor system the Biot heat dimensionless number calculated is very low (0.0955), and Biot mass dimensionless number is very high (86.66). Therefore the rate limiting steps for the system seems to be the intraparticle (micro and/or macropores) mass transfer and external heat transfer.

The change in the amount adsorbed by the clinoptilolite with time for particle size of $0.32 \mathrm{~cm}$ (Fig. 2) was used to obtain the uptake curves $\left(M_{\mathrm{t}} / M_{\mathrm{e}}\right.$ $v s . t)$. The initial range $\left(0.3<M_{\mathrm{t}} / M_{\mathrm{e}}\right)$ of the curves is linear and its slope change with water vapor dose pressure and particle size (Fig. 3). An analysis of the uptake curves obtained for two different particles at

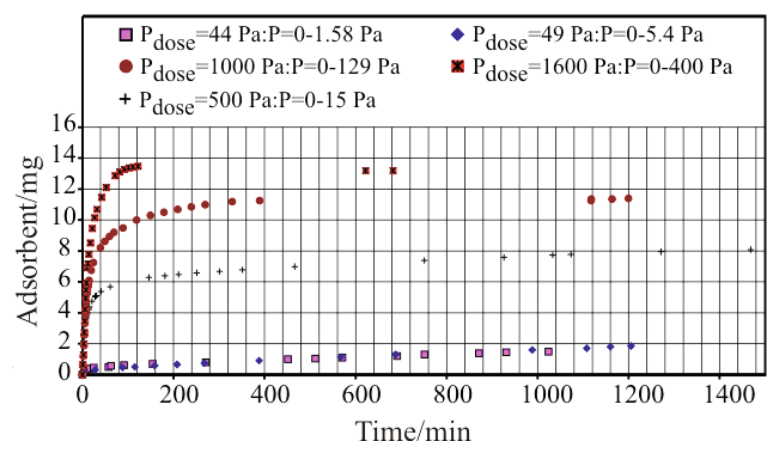

Fig. 2 The change in the amount adsorbed by clinoptilolite $\left(R_{\mathrm{p}}=0.32 \mathrm{~cm}\right)$ with time
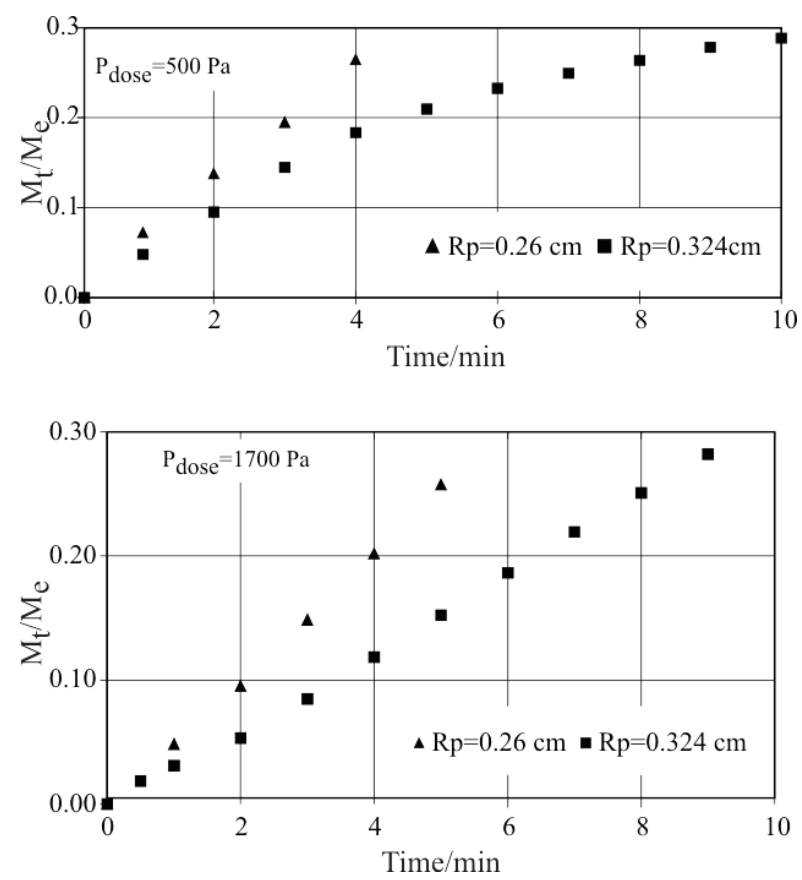

Fig. 3 Experimental uptake curves for clinoptilolite

the same dose pressure shows that its slope is lower for the big particle.

\section{Sorption kinetics and modeling}

The transport of water vapor in a natural zeolitic tuff is a very complex process. It consists of small microporous crystals embedded macroporous non-zeolitic phases such as quartz and calcite. So it is likely that transfer processes in micropore, and macropore could make contribution to water adsorption on zeolite. The macropore diffusion is generally faster than micropore diffusion because of a great difference between the pore sizes (micropore: up to $2.0 \mathrm{~nm}$; macropore: $>50 \mathrm{~nm}$ [14]. In the description of the transport of the water in such a porous spherical particle, Fick's Law can be expressed as:

$$
\frac{\partial q}{\partial t}=\frac{D_{\mathrm{e}}}{R_{\mathrm{p}}^{2}} \frac{\partial}{\partial R}\left(R^{2} \frac{\partial q}{\partial r}\right)
$$

The assumptions were made:

- The transport is considered to be one-dimensional

- The system thermodynamically ideal so the diffusivity is independent of the adsorptive concentration.

- The amount adsorbed by adsorbent is comparable with adsorptive in the system.

The solution of Eq. (1) for the following boundary conditions in a spherical particle: 
Table 1 Water vapor adsorption kinetic data

\begin{tabular}{rrccc}
\hline$P_{\text {dose }} / \mathrm{Pa}$ & $P_{\mathrm{e}} / \mathrm{Pa}$ & $q_{\mathrm{e}} / \mathrm{mg} \mathrm{mg}^{-1}$ & $D_{\mathrm{e}} \cdot 10^{6} / \mathrm{cm}^{2} \mathrm{~s}^{-1}$ & $D_{\mathrm{e}} / R_{\mathrm{p}}^{2} \cdot 10^{6} / \mathrm{s}^{-1}$ \\
\hline \multicolumn{1}{c}{} & & & \\
500 & 4 & $R_{\mathrm{p}}=0.26 \mathrm{~cm}$ & 0.117 \\
1000 & 15 & 0.075 & 0.012 & 0.937 \\
1700 & 82 & 0.084 & 0.098 & 7.500 \\
\hline & 500 & 0.106 & 0.787 & 28.300 \\
\hline 44 & & 0.128 & 2.971 & 3.750 \\
49 & 2 & $R_{\mathrm{p}}=0.32 \mathrm{~cm}$ & 1.880 \\
1000 & 5 & 0.016 & 0.254 & 1.880 \\
1600 & 15 & 0.020 & 0.127 & 28.300 \\
\hline
\end{tabular}

$P_{\text {dose }}$ and $P_{\mathrm{e}}$ : the dose and equilibrium pressure, respectively; $q_{\mathrm{e}}$ : the amount adsorbed; $R_{\mathrm{p}}$ : radius of particle

$$
\begin{gathered}
t=0 \quad q=0 \\
t>0 R=R_{\mathrm{p}} q=q^{*} \\
t>0\left(\frac{\partial q}{\partial R}\right)_{\mathrm{R}=0}=0
\end{gathered}
$$

is:

$$
\frac{\bar{q}}{q^{*}}=\frac{M_{t}}{M_{e}}=1-\frac{6}{\pi^{2}} \sum_{\mathrm{n}=1}^{\infty} \frac{1}{n^{2}} \exp \left(-\frac{n^{2} \pi^{2} D_{\mathrm{e}} t}{R_{\mathrm{p}}^{2}}\right)
$$

where $D_{\mathrm{e}}$ is the apparent intra particle diffusion coefficient. The average amount adsorbed within the particle

$$
\bar{q}=\frac{3}{R_{\mathrm{p}}^{3}} \int_{0}^{\mathrm{R}_{\mathrm{p}}} q R^{2} d R
$$

where $R_{\mathrm{p}}$ is radius of particle.

Apparent diffusion coefficient of water vapor in the clinoptilolite was calculated by using Eq. (3) and presented on Table 1. The diffusion coefficients were

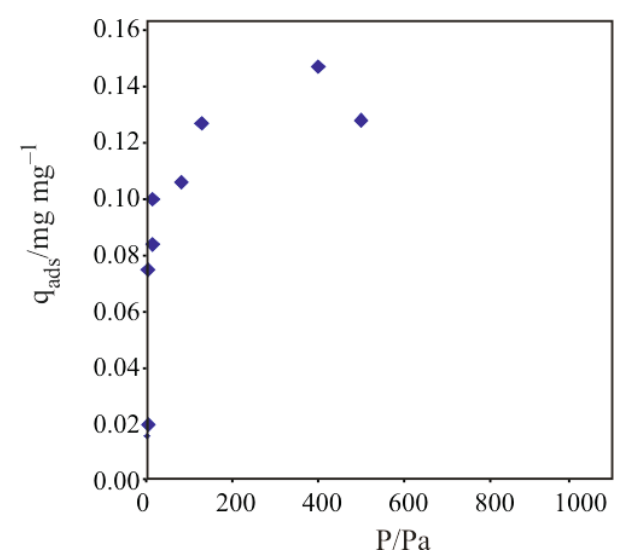

Fig. 4 Water vapor adsorption isotherm on natural zeolite $\left(T=18^{\circ} \mathrm{C}\right)$ not changed significantly with amount adsorbed up to 0.1 ( $\mathrm{mg} / \mathrm{mg}$ ) whereas increased considerably at higher amount adsorbed. Figure 4 shows the water vapor adsorption isotherm on natural zeolite. It can be concluded that in the range of Henry's Law (up to $0.1 \mathrm{mg} / \mathrm{mg}$ of amount adsorbed) diffusion progressed slowly enough to neglect heat effect. Apparent diffusion time constant, $D_{\mathrm{e}} / R_{\mathrm{p}}^{2}$ are also evaluated and presented in Table 1. As seen from the table diffusion time constant was not affected by particle size showing that the diffusion in micropore was the
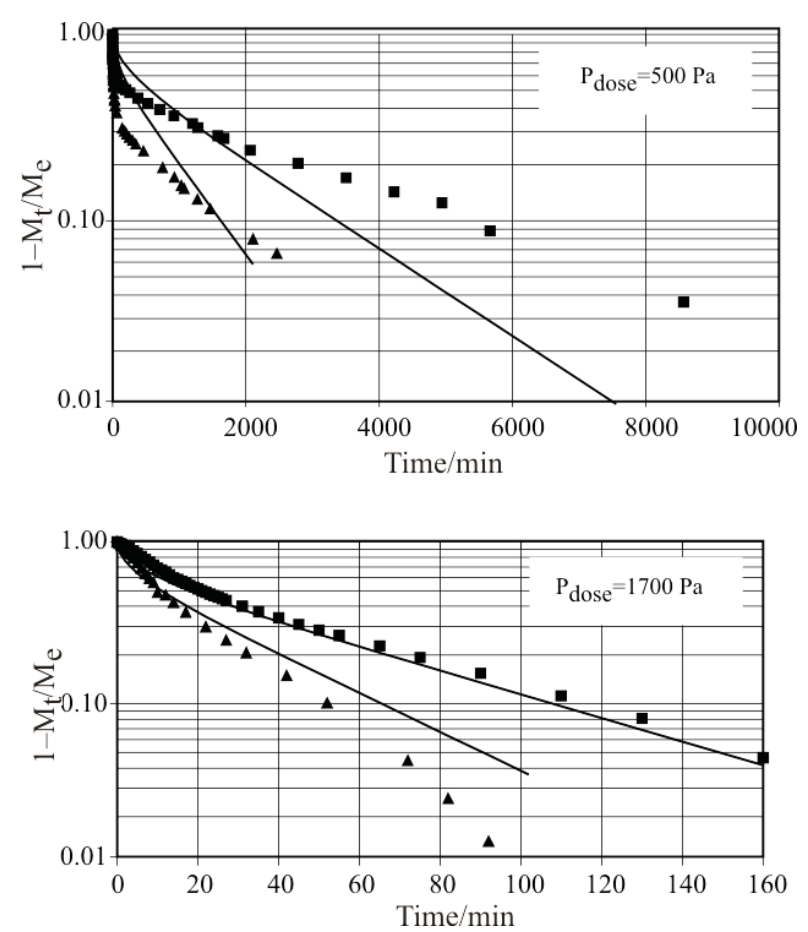

Fig. 5 Theoretical (line) and experimental $\left(-R_{\mathrm{p}}=0.32 \mathrm{~cm}\right.$; $\Delta-R_{\mathrm{p}}=0.26 \mathrm{~cm}$ ) uptake curves for $P_{\text {dose }}=500 \mathrm{~Pa}$ (upper) and $P_{\text {dose }}=1700 \mathrm{~Pa}$ (lower) 


\section{ÇAKICIOĞLU-OZKAN, ÜLKÜ}

controlling step. Figure 5 shows the experimental uptake curves fitted by the isothermal model Eq. (3). As seen from the figures there is good agreement with the model at high dose pressure and particle size. With high amount of adsorptive (high dose pressure) the heat evolved can easily be removed from the surface. On the other hand the temperature profile can not form easily in the larger particle. So the intraparticle mass transfer is responsible for the water vapor adsorption and the system behaves as isothermal for high dose pressure and particle size.

\section{Conclusions}

The adsorption kinetics of $\mathrm{H}_{2} \mathrm{O}$ in clinoptilolite rich zeolitic tuff particles having 0.24 and $0.32 \mathrm{~cm}$ diameter was experimentally investigated at $18^{\circ} \mathrm{C}$. The change of mass vs. time were recorded by admitting water vapor to the system at different dose pressures. Isothermal adsorption model equation was applied to the data for the identification of the diffusion mechanism. It was found that the intraparticle mass transfer becomes more dominant over the heat transfer with increase in particle size and the adsorptive dose pressure. Although initially intraparticle mass transfer was the controlling resistance later external heat transfer also contributes to the transfer mechanism.

\section{References}

1 D. W. Breck, Zeolites: Molecular Sieves, Wiley-Interscience, New York 1980.

2 S. Ulku, D. Balkose, H. Baltacioglu, F. Ozkan and A. Yıldırım, Drying Technol., 10 (1992) 475.

3 S. Ulku, Z. Kivrak and M. Mobedi, A. S. Mujumdar (Ed.) Drying 86, Hemisphere Pub. Corp. Washington 1986, p. 807.

4 S. Ulku and F. Ozkan (Cakıcıglu), Renewable Energy, 1 (1991) 695.

5 S. Ulku and G. Uckan, A. S. Mujumdar (Ed.) Drying 86, Hemisphere Pub. Corp. Washington 1986, p. 531.

6 D. Sternik, P. Staszczuk, M. Majdan, A. Gladysz-Plaska, E. Dabrowska and K. Bigda, J. Therm. Anal. Cal., 86 (2006) 69.

7 S. Ulku, J. Heat Recovery Systems, 6 (1986) 277.

8 S.Ulku and M. Mobedi, B. K1lk1s, S. Kakac (Eds), Energy Storage Systems, Nato ASI series E: 167, Kluwer Academic Pub., London 1989, p. 487.

9 S. Ülkü, D. Balköse, T. Çağa, F. Özkan and S. Ulutan, Adsorption, 4 (1998) 63.

10 D. Balköse, F. Özkan, S. Ulutan and S. Ülkü, J. Therm. Anal. Cal., 71 (2003) 89.

11 F.Ozkan, Ph.D. Thesis, Ege University, Izmir 1996.

12 F. C. Ozkan and S. Ulku, Micropor. Mesopor. Mater., 77 (2005) 47.

13 G. V. Tsitsishvili, T. G. Andronikashvili, G. N. Kirov and L. D. Filizova, Natural Zeolites, Ellis Horwood, New York 1992.

14 D. M. Ruthven, Principle of Adsorption and Adsorption Processes, J. Wiley and Sons Inc. 1984.

DOI: $10.1007 / \mathrm{s} 10973-008-9357-8$ 